\title{
INFLUENCIA DA ESTRUTURA DE PROPRIEDADE E DO GERENCIAMENTO FAMILIAR SOBRE O POSICIONAMENTO EM FUSÕES E AQUISIÇÕES*
}

\author{
GEOVANNE DIAS DE MOURA* \& ILSE MARIA BEUREN"** \\ UNIVERSIDADE COMUNITÁRIA DA REGIÃO DE CHAPECÓ (BRASIL)- UNIVERSIDADE FEDERAL DE SANTA \\ CATARINA (BRASIL)
}

Recibido/ Received/ Recebido: 26/01/2015-Aceptado/ Accepted / Aprovado: 24/06/2016

\begin{abstract}
Resumo
Este estudo pesquisa a influência da estrutura de propriedade e de gerenciamento familiar sobre o posicionamento em operações de fusões e aquisições de empresas que cotizam no mercado BM\&FBovespa. Para tal fim, fez-se uma pesquisa descritiva com enfoque quantitativo, por meio de análise documental, em uma mostra de 338 companhias posicionadas em operações de fusões e aquisições, no período 2007 a 2012. Os resultados mostram que as empresas com estrutura de propriedade familiar envolvidas em fusões e aquisições, tendem a tomar uma posição ativa, isto é, como compradores. Além do mais, que o gerenciamento da família influi na posição como empresa compradora neste tipo de operações. Conclui-se que as famílias são investidoras que valorizam o controle acionário, adotam políticas de gerenciamento guiadas pela aversão ao risco e pela busca de um melhor rendimento e, por isto, se posicionam como compradores em fusões e aquisições.

Palavras chave: Gestão; Propriedade familiar; Posicionamento; Fusões e Aquisições.
\end{abstract}

\section{INFLUENCIA DE LA ESTRUCTURA DE PROPIEDAD Y DE LA GESTIÓN FAMILIAR SOBRE EL POSICIONAMIENTO EN FUSIONES Y ADQUISICIONES}

\begin{abstract}
Resumen
Este estudio investiga la influencia que tienen la estructura de propiedad y de gestión familiar sobre el posicionamiento en operaciones de fusiones y adquisiciones de empresas que cotizan en el mercado BM\&FBovespa. Para tal fin, se hizo una investigación descriptiva con enfoque cuantitativo, por medio de análisis documental, en una muestra de 338 compañías posicionadas en operaciones de fusiones y adquisiciones, en el periodo 2007 a 2012. Los resultados muestran que las empresas con estructura de propiedad familiar envueltas en fusiones y adquisiciones, tienden
\end{abstract}

\footnotetext{
Artigo de investigação científica.

* Doutor em Ciências Contábeis e Administração pela Universidade Regional de Blumenau - FURB, professor da Universidade Comunitária da Região de Chapecó - UNOCHAPECÓ. Endereço: Avenida Senador Atílio Fontana-Servidão Anjo da Guarda, 591-E-Bairro Efapi. CEP: 89809-900 - Chapecó/SC - Brasil. Telefone: (49) 3321-8000. E-mail: geomoura@terra.com.bro

... Doutora em Controladoria e Contabilidade pela FEA/USP, professora do Programa de Pós-Graduação em Contabilidade da Universidade Federal de Santa Catarina - UFSC. Endereço: Centro Socioeconômico, Campus Universitário, Trindade. CEP: 88040970 - Florianópolis/SC - Brasil. Telefone: (48) 3721-6608. E-mail: ilse.beuren@gmail.com
} 
a tomar una posición activa, es decir, como compradores. Además, que la gestión de la familia influye en la posición como empresa compradora en este tipo de operaciones. Se concluye que las familias son inversores que valoran el control accionario, adoptan políticas de gestión guiadas por la aversión al riesgo y la búsqueda de un mejor rendimiento y, por tanto, se posicionan como compradores en fusiones y adquisiciones.

Palabras clave: Gestión; Propiedad familiar; Posicionamiento; Fusiones y Adquisiciones.

\title{
INFLUENCE OF OWNERSHIP STRUCTURE AND FAMILY MANAGEMENT ON POSITIONING IN MERGERS AND ACQUISITIONS
}

\begin{abstract}
This study investigates the influence of the ownership structure and family management on positioning in mergers and acquisitions of companies listed on the BM \& FBovespa market. For this purpose a descriptive research with quantitative approach, through documentary analysis in a sample of 338 companies positioned in mergers and acquisitions in the period 2007 to 2012 was performed. The results show that companies with a structure of family ownership involved in mergers and acquisitions tend to take an active position as buyers. Moreover, the family management influences in the position as acquiring company in such operations. It is concluded that families are investors who value the stock control, adopt management policies guided by risk aversion and the search for better return and therefore position themselves as buyers in mergers and acquisitions. Keywords: Management; Family property; Positioning; Fusions and Acquisitions.
\end{abstract}

Dias, G. \& Beuren, I. (2017). Influência da estrutura de propriedade e do gerenciamento familiar sobre o posicionamento em fusões e aquisições. En: Revista de la Facultad de Ciencias Económica: Investigación y Reflexión. rev.fac.cienc.econ, XXV (1). DOI: http://dx.doi. org/10.18359/rfce.2658

JEL: G10, G34.

\section{Introdução}

As decisões para o envolvimento das empresas em fusões e aquisições estão relacionadas às suas estratégias de crescimento, interno ou externo, sendo este último baseado em fusões e aquisições (Caprio, Croci \& Del Giudice, 2011; Yoo, Lee \& Heo, 2013). Tanto o tipo de estrutura de propriedade quanto o tipo de gestão podem influenciar na decisão de fazer aquisições, aceitar ofertas públicas de aquisição, promover o envolvimento em fusões e de se posicionar como empresa adquirente ou adquirida (Villalonga \& Amit, 2006; Caprio, Croci \& Del Giudice, 2011).
Na estrutura de propriedade, conforme Shim \& Okamuro (2011), tais operações tendem a diminuir a concentração acionária do controlador, dependendo do tamanho relativo da empresa adquirida. Segundo eles, na maioria das operações, parte do pagamento é efetuado com ações da própria companhia adquirente. Então, é de se esperar que empresas controladas por famílias sejam menos propensas a se envolverem em operações de fusões e aquisições, principalmente, devido ao temor que as famílias tem de perder o controle, especialmente se a companhia for da família por várias gerações (Shim \& Okamuro, 2011). 
Estudos, como os de Gómez, Makri \& Kintana (2010), Miller, Le Breton-Miller \& Lester (2010), Shim \& Okamuro (2011) e Caprio, Croci \& Del Giudice (2011), sugerem que a valorização do controle acionário, por parte do controlador familiar, tem um impacto significativo sobre as decisões estratégicas de crescimento por meio de fusões $e$ aquisições, como também para o posicionamento ativo como adquirente nessas operações.

Em relação à influência da gestão no posicionamento, é importante destacar que, no caso de estrutura de propriedade familiar, muitas vezes, o próprio controlador ou um membro da família é responsável pela gestão. Porém, nem sempre a gestão é realizada pela família. A família poderá optar, por exemplo, pela contratação de uma gestão não familiar, ou seja, realizada por profissionais que não fazem parte da família. Nos casos em que a estrutura de propriedade é do tipo não familiar, a gestão também será do tipo não familiar (Gomez, Nunez \& Gutierrez, 2001; Miller, Le Breton-Miller, Lester \& Cannella Jr, 2007).

As fusões e aquisições são operações de risco elevado, visto que os benefícios futuros esperados desse tipo de investimento são incertos. Por essa razão, é menor a probabilidade de envolvimento de uma empresa que possui gestão familiar nesse tipo de operações. Isso ocorre porque famílias são investidores pouco diversificados e que enfrentam alto risco de exposição a um único ativo, ou seja, a empresa da família (Bianco, Bontempi, Golinelli \& Parigi, 2013; Schmid, 2013). O desejo de proteger o patrimônio da família faz com que o gestor familiar evite o envolvimento em operações de risco elevado, que é o caso das fusões e aquisições (Anderson \& Reeb, 2003a; Caprio, Croci-Del \& Del Giudice, 2011; Gomez, Cruz, Berrone \& Castro, 2011).

Por outro lado, uma empresa de gestão profissional estará mais propensa a se envolver em uma operação de fusão ou aquisição, visando especialmente à obtenção de benefícios próprios, tais como, oportunidades de emprego futuro ou, então, indenizações volumosas (Villalonga \& Amit, 2006; Shim \& Okamuro, 2011). O gestor contratado terá um ônus financeiro inferior ao do proprietário e estará mais propenso ao envolvimento em operações de riscos (Tsai, Kuo \& Hung, 2009; Caprio, Croci \& Del Giudice, 2011). Além disso, quando a gestão não é familiar, haverá maior tendência para um posicionamento passivo, ou seja, como adquirida nessas operações (Shim \& Okamuro, 2011).

O desempenho da gestão também pode influenciar no posicionamento em uma operação de fusão ou aquisição. No caso de restrições financeiras, oriundas de desempenho inferior, a gestão poderia priorizar o crescimento interno e abrir mão de novas oportunidades de investimento. Por outro lado, um desempenho superior facilita e influencia o posicionamento ativo como adquirente nessas operações (Caprio, Croci \& Del Giudice, 2011; Shim \& Okamuro, 2011).

Tanto a valorização do controle acionário das empresas com estrutura de propriedade familiar, quanto a aversão ao risco e o desempenho da gestão familiar tem despertado interesse crescente na literatura sobre a estratégia de negócios e a economia financeira, principalmente, em consequência da expressiva representação das empresas familiares no atual cenário econômico global (Villalonga \& Amit, 2006; Hiebl, 2012). No entanto, a influência da estrutura de propriedade e da gestão familiar na decisão de se envolver em fusões ou aquisições e de se posicionar como empresa adquirente ou adquirida são lacunas de pesquisa (Villalonga \& Amit, 2006; Caprio, Croci \& Del Giudice, 2011).

Com base no exposto, a questão de pesquisa que orienta este estudo é: Qual a influência da estrutura de propriedade e da gestão familiar no posicionamento como empresa adquirente ou adquirida em operações de fusões e aquisições? Assim, o objeto do estudo consiste em verificar a influência da estrutura de propriedade e da gestão familiar no posicionamento em operações de fusões e aquisições de empresas listadas na BM\&FBovespa.

O estudo justifica-se tanto em termos de práticas empresariais, como das investigações na perspectiva teórica, particularmente no que concerne às empresas de propriedade e de gestão familiar. Fusões e aquisições são opções estratégicas disponíveis no 
mercado para o crescimento das empresas, por isso, tornam-se cada vez mais comuns no mundo dos negócios. Por conseguinte, o tema também tornou-se crescente e relevante em discussões no meio acadêmico (Bjursell, 2011). No entanto, o número de pesquisas nessa área ainda é pequeno, conforme Ferreira, Santos, Almeida \& Reis (2014), apesar da relevância do tema.

Mickelson \& Worley (2003), Bjursell (2011), Caprio, Croci \& Del Giudice (2011) e Shim \& Okamuro (2011) salientam que menor ainda é o número de estudos empíricos sobre fusões e aquisições relacionados às empresas familiares. Embora a literatura sobre fusões e aquisições esteja crescendo, ainda há várias lacunas de pesquisa sobre a influência das famílias no posicionamento em operações de fusões e aquisições. Assim, o estudo contribui para essas lacunas de pesquisa constatadas na revisão da literatura, além de destacar a relevância das análises da estrutura de propriedade e da gestão familiar.

\section{Referencial teórico}

Nesta seção, apresenta-se o referencial teórico que visa consubstanciar o desenvolvimento do estudo empírico. Inicialmente, aborda-se sobre fusões $e$ aquisições de empresas. Em seguida, discorre-se sobre a influência da valorização do controle acionário, da aversão ao risco empresarial e do desempenho em operações de fusões e aquisições de empresas.

\subsection{Operações de fusões e aquisições}

O crescimento das empresas pode ser dividido em crescimento interno e externo. O crescimento interno é uma estratégia que decorre da acumulação de lucros, racionalização de custos, aumento da produção, aumento das vendas, entre outras. Por sua vez, o crescimento externo é uma estratégia que se materializa pela aquisição de alguns ou de todos os ativos de outra empresa, é baseado principalmente em fusões e aquisições (Caprio, Croci \& Del Giudice, 2011; Yoo, Lee \& Heo, 2013).

Em função da complexidade das operações das companhias, é possível que elas não possam intensificar o crescimento somente de forma interna, nas atividades operacionais. Por isso, as transações de fusões e aquisições são amplamente usadas como estratégia para superar as limitações impostas por uma baixa velocidade do crescimento interno $e$ acelerar a criação de valor, seja na perspectiva de aumentar a participação de mercado, obtenção de sinergias ou mesmo na consolidação de vantagem competitiva (Bjursell, 2011; Chi, Sun \& Young, 2011).

Fusões e aquisições, conforme Granata \& Chirico (2010), tornaram-se uma importante estratégia de crescimento externo, que possibilita empresas obterem recursos complementares.

Fusão, de acordo com o art. 228 da Lei $\mathrm{n}^{\circ}$ $6.404 / 76$, "[...] é a operação pela qual se unem duas ou mais sociedades para formar sociedade nova, que lhes sucederá em todos os direitos e obrigações". As pessoas jurídicas envolvidas se extinguem, dando origem a uma nova pessoa jurídica que receberá, por transferência, todos os ativos $e$ passivos das companhias fundidas (Lemes, Rigo \& Cherobim, 2002; Granata \& Chirico, 2010).

Em países desenvolvidos, como nos Estados Unidos, há muitos anos as operações de fusões e aquisições são concretizadas somente depois de terem sido autorizadas previamente pelos órgãos competentes. No Brasil, a avaliação prévia, até o ano de 2012, era optativa para as empresas e não uma obrigação. Sendo assim, várias optavam por realizar a operação e depois submetê-la aos órgãos de defesa da concorrência. Nesses casos, se não fosse aprovada, o risco era ter que desfazer o negócio. Todavia, depois de iniciado o processo, era raro reverter a união (Lemes, Rigo \& Cherobim, 2002).

A Lei no 12.529 , de 29 de maio de 2012, reformulou o Sistema Brasileiro de Defesa da Concorrência (SBDC) e tornou mais eficaz a atuação do Conselho Administrativo de Defesa da Concorrência (CADE). A principal mudança introduzida por esta Lei consiste na exigência de submissão prévia ao CADE de fusões e aquisições de empresas que possam ter efeitos anticompetitivos. Pela legislação anterior, essas operações podiam ser comunicadas ao Cade depois de serem consumadas, o que fazia do Brasil 
um dos únicos países do mundo a adotar um controle a posteriori de estrutura.

Aquisição é um método que possibilita obter direito de controle pela compra de ações e/ou ativos de uma empresa, ou seja, uma empresa (adquirente) adquire outra empresa (adquirida) (Lemes, Rigo \& Cherobim, 2002; Yoo, Lee \& Heo, 2013). A aquisição de companhias pode ocorrer de forma amigável ou de forma hostil. A aquisição amigável ocorre mediante negociação e consentimento dos órgãos internos de administração da companhia alvo (Feito \& Menéndez, 2010; Gleason, Pennathur \& Wiggenhorn, 2014). Os acionistas da companhia adquirida podem receber o pagamento pela venda de suas ações em dinheiro, ou parte em dinheiro e parte em ações da companhia adquirente. Já a aquisição hostil ocorre quando uma companhia lança oferta na tentativa de adquirir outra companhia, independente da administração dessa ter interesse ou não (Feito \& Menéndez, 2010; Gleason, Pennathur \& Wiggenhorn, 2014).

A partir do exposto e com foco na sustentação teórico-empírica do estudo, na sequência são abordadas questões relativas à valorização do controle acionário, aversão ao risco empresarial e desempenho das empresas, e como estas questões influenciam no posicionamento das empresas familiares $e$ não familiares em operações de fusões e aquisições.

\subsection{Valorização do controle acionário em operações de fusões e aquisições}

O envolvimento em uma operação de fusão ou aquisição pode implicar em perda do controle. Isso ocorre porque essas operações tendem a diminuir a concentração acionária do controlador da empresa adquirente, dependendo do tamanho da empresa adquirida (Shim \& Okamuro, 2011). Empresas com estrutura de propriedade familiar, cuja principal característica é a concentração de propriedade, presume-se que sejam menos propensas a se envolverem em operações de fusões ou aquisições, pelo medo de perder o controle, especialmente se a companhia for da família por várias gerações (Shim \& Okamuro, 2011).
A empresa, além de ser uma fonte de renda da família, é uma fonte de orgulho. Portanto, em casos como esses, quando a participação acionária detida pela família controladora não for grande o suficiente para assegurar a persistência do controle em posse da família, após uma operação de fusão, por exemplo, dificilmente esta operação ocorrerá (Caprio, Croci \& Del Giudice, 2011; Bouzgarrou \& Navatte, 2013).

Schmid (2013) relata que a própria reputação da família está ligada ao prestígio, sucesso e patrimônio que a empresa obteve ao longo dos anos. Portanto, as famílias são especialmente preocupadas com a perda do controle da empresa. Diante da possibilidade de perda de controle, presume-se que empresas familiares tendem a evitar o crescimento externo, por fusões ou aquisições, e valorizar o crescimento interno, com suas atividades operacionais.

Em contraste a esse ponto, Shim \& Okamuro (2011) destacam que em empresas não familiares, principalmente as de capital disperso, em que grande parte dos acionistas não têm ou, no máximo, detém uma parte insignificante da propriedade, não haverá esta preocupação. Em empresas não familiares, ou até mesmo em empresas familiares com gestão profissional, haverá menor valorização pelo controle acionário, maior tendência a conflitos de agência e maior possibilidade de envolvimento em fusões ou aquisições com fins oportunistas.

Motivos não-monetários também são destacados por Bjursell (2011) para a valorização do controle acionário pelas famílias, pois a empresa simboliza herança e tradição da família, faz parte da própria identidade da família. A família controladora frequentemente pretende passar a empresa para as gerações futuras, por conseguinte, é necessário manter o negócio em condições favoráveis. Estes motivos, além de aumentar a valorização do controle acionário, influenciam para que as empresas familiares assumam posição ativa, como adquirente e não como adquirida, caso se envolvam em fusões e aquisições.

Estudos como de Gómez, Makri \& Kintana (2010), Miller, Le Breton-Miller \& Lester (2010), Caprio, Croci \& Del Giudice (2011), e Shim \& Okamuro (2011) também sugerem que a valorização do 
controle acionário, por parte das famílias, tem um impacto significativo sobre as decisões estratégicas de crescimento por meio de fusões e aquisições $e$ para o posicionamento ativo como adquirente.

Depreende-se a partir da revisão da literatura apresentada, que a empresa familiar é uma fonte de orgulho e de renda da família, o patrimônio da empresa familiar geralmente é formado ao longo de anos, famílias têm expectativa de transferir a empresa para gerações futuras, especialmente se a companhia for da família durante várias gerações. Assim, as famílias não abrirão mão do controle tão facilmente, $e$ caso se envolvam em fusões ou aquisições, assumirão uma posição ativa, ou seja, como adquirentes.

Depreende-se da revisão da literatura apresentada, que a empresa familiar é uma fonte de orgulho e de renda da família. Além disso, o patrimônio da empresa familiar geralmente é formado ao longo de décadas e que as famílias têm expectativa de transferir esse patrimônio para gerações futuras, especialmente se a empresa pertencer à família durante várias gerações. Assim, as famílias não abrirão mão do controle tão facilmente, e caso se envolvam em fusões ou aquisições, assumirão uma posição ativa, ou seja, como adquirentes.

\subsection{Aversão ao risco empresarial no momento do posicionamento em fusões e aquisições}

Fusões e aquisições são operações que envolvem riscos de negócios, pois, os benefícios futuros esperados por meio deste tipo de investimento são incertos. Portanto, estas operações expõem os gestores a maiores níveis de incerteza. Harding \& Rovit (2005) mencionam que cerca de $70 \%$ de todas as transações fracassam em criar valor para a empresa adquirente ou seus acionistas. Desse modo, empresas familiares, em razão de possuírem maior aversão ao risco, tendem a adotar estratégias de aquisição mais cautelosas do que empresas não familiares. Isso ocorre porque o desejo de proteger o patrimônio da família faz com que o gestor evite operações de risco elevado (Gómez et al. 2011).

Famílias, por serem investidores pouco diversificados e com grande participação acionária nas empresas que possuem, enfrentam alto risco de exposição a um único ativo (Bianco et al., 2013; Schmid, 2013). Gonenc, Hermes \& Sinderen (2013) ressaltam que controladores familiares, por serem um tipo de acionistas que detém carteiras de investimento pouco diversificadas, têm menor preferência por estratégias de negócios arriscadas. Logo, tais empresas terão maiores incentivos para adotarem medidas de redução de riscos.

Evitar operações de fusões e aquisições pode ser uma dessas medidas, conforme expõem Miller, Le Breton-Miller \& Lester (2010), Caprio, Croci \& Del Giudice (2011), e Shim \& Okamuro (2011). Outra medida seria, no caso de envolvimento em fusões e aquisições, assumir uma posição ativa, como adquirente, e não como adquirida, para continuar zelando pelo patrimônio da família após a operação (Caprio, Croci \& Del Giudice, 2011; Shim \& Okamuro, 2011). Proprietários familiares, conforme Miller, Le Breton-Miller \& Lester (2010), procuram construir relacionamentos duradouros com as partes interessadas, dentro e fora da empresa, para sustentar o negócio e reduzir riscos. Para os autores, famílias, preocupadas com a longevidade das suas empresas, evitam estratégias de continuidade, como fusões $e$ aquisições, que podem gerar ações potencialmente desestabilizadoras. Porém, no caso de envolvimento em uma dessas operações, empresas familiares tendem a assumir uma posição ativa, como adquirente, para que possam seguir com suas políticas de gestão.

Se uma operação de fusão ou aquisição resultar em fracasso financeiro, tal acontecimento poderia prejudicar a imagem, reputação e nome da família, características que são importantes para os proprietários familiares. Bouzgarrou \& Navatte (2013) consideram as famílias como investidores com visão de longo prazo e que mantém posições sustentáveis em suas empresas, logo, tendem a ser avessas ao risco oriundo de fusões e aquisições. Todavia, ao se envolverem nesse tipo de operação, como um meio de expansão dos negócios, pode significar que tais empresas esperam que o negócio seja rentável o suficiente para compensar o risco (Shim \& Okamuro, 2011).

Miller, Le Breton-Miller \& Lester (2010) apresentam outro fator que influencia para que empresas familiares não se envolvam em fusões e aquisições. Eles observam que, nestas operações, a preocupação dos 
controladores familiares em manter o controle acionário em posse da família exige, muitas vezes, altos financiamentos, que podem aumentar o perfil de risco da empresa. O financiamento, segundo Miller, Le Breton-Miller \& Lester (2010), contribui para um posicionamento como adquirente, mas, por outro lado, a possibilidade de endividamento pode influenciar para que a operação não se concretize. Pois, além do risco relacionado à operação de fusão ou aquisição, a empresa pode perder a liberdade para definir suas políticas de negócios, especialmente por condições impostas pelos bancos em virtude dos financiamentos (Gallo, Tapies \& Cappuyns, 2004).

Depreende-se a partir da revisão da literatura apresentada, que famílias, em virtude de possuírem maior aversão ao risco, tendem a adotar estratégias de aquisição mais cautelosas do que as empresas não familiares. Em razão de serem investidores pouco diversificados, terão maiores incentivos para proteger o patrimônio da empresa e, consequentemente, buscar uma posição ativa, como adquirente, em fusões e aquisições, para que possam seguir com suas políticas de gestão mais conservadoras. No caso de envolvimento em fusões e aquisições, assumir uma posição ativa, como adquirente e não como adquirida, implicaria em continuar zelando pelo patrimônio da família após a operação.

Infere-se do exposto, em virtude de possuírem maior aversão ao risco, famílias tendem a adotar estratégias de aquisição mais cautelosas em comparação a empresas não familiares. Em razão de serem investidores pouco diversificados, famílias terão maiores incentivos para proteger o patrimônio da empresa e, consequentemente, buscar uma posição ativa, como adquirente, em fusões e aquisições, para que possam seguir com suas políticas de gestão mais conservadoras. No caso de envolvimento em fusões e aquisições, assumir uma posição ativa, como adquirente e não como adquirida, implica em continuar zelando pelo patrimônio da família após a operação de fusão ou aquisição.

\subsection{Desempenho da empresa em operações de fusões e aquisições}

Outro fator que pode influenciar em operações de fusões e aquisições é o desempenho. A baixa pro- pensão das empresas familiares para se envolverem em fusões ou aquisições pode ser em função das consequências de restrições financeiras. Menor valor e desempenho inferior, no comparativo com empresas não familiares, poderia levá-las a priorizar o crescimento interno e abrir mão de novas oportunidades de investimento (Caprio, Croci \& Del Giudice, 2011; Shim \& Okamuro, 2011).

Portanto, a baixa propensão de empresas familiares às fusões e aquisições pode estar associada, entre outros aspectos, com um menor valor e desempenho. No entanto, Caprio, Croci \& Del Giudice (2011) afirmam que empresas familiares se envolvem em aquisições com menor frequência do que as empresas não familiares, mas, sem afetar negativamente o seu crescimento e desempenho.

Pela perspectiva principal-agente da Teoria da Agência, a gestão familiar tem mais incentivos para gerir devidamente as empresas, reduzir regalias excessivas e, assim, melhorar o desempenho, porque seus interesses são altamente alinhados com o controlador familiar e demais acionistas não familiares (Anderson \& Reeb, 2003a; Jiang \& Peng, 2011; Cai, Luo \& Wan, 2012).

No entanto, mesmo as empresas familiares sendo o tipo dominante em todo o mundo, poucos estudos têm investigado a influência do desempenho de empresas familiares e não familiares em operações de fusões e aquisições (Shim \& Okamuro, 2011). Dessa forma, a influência do desempenho em tais operações ainda figura como lacuna que requer investigações (Villalonga \& Amit, 2006; Caprio, Croci \& Del Giudice, 2011).

Apesar de poucas análises empíricas, especula-se que o desempenho, a valorização do controle acionário e a aversão ao risco podem influenciar na decisão de realizar aquisições, aceitar as ofertas públicas de aquisição, para o envolvimento em fusões, ou ainda, na decisão de se posicionar como adquirente ou como empresa adquirida, embora esses fatores tenham sido pouco abordados em pesquisas empíricas (Caprio, Croci \& Del Giudice, 2011).

O principal argumento é que empresas familiares apenas se envolverão de forma passiva, como 
adquiridas, em fusões e aquisições, se o valor e desempenho forem baixos e se esta for uma das últimas alternativas para a continuidade do negócio. Caso contrário, famílias dificilmente abandonarão o controle de suas empresas (Caprio, Croci \& Del Giudice, 2011; Shim \& Okamuro, 2011).

Além disso, o efeito das fusões e aquisições no desempenho operacional pode ser diferente entre empresas familiares e não familiares. Se as famílias tendem a evitar fusões e aquisições devido aos riscos de negócios e pelo medo de perder o controle, então, quando decidem prosseguir com essas operações, pode significar que elas esperam que a operação seja rentável o suficiente para compensar qualquer tipo de risco (Shim \& Okamuro, 2011).

Para se envolverem em operações de fusões e aquisições como adquirentes, empresas familiares precisam de maior valor e melhor desempenho. Nesse sentido, Bouzgarrou \& Navatte (2013) mencionam que as empresas familiares são mais cautelosas no momento de selecionar a empresa alvo, mais eficientes durante todo o processo de integração $e$, na maioria dos casos, se envolvem em tais operações apenas a fim de criar valor, por isso, tendem a assumir uma posição ativa, como adquirentes.

Com base na revisão da literatura apresentada, nota-se que empresas familiares apenas se envolverão de forma passiva, como adquiridas, em fusões $e$ aquisições, se o valor e o desempenho forem baixos e se esta for uma das últimas alternativas para a continuidade do negócio. Caso contrário, famílias dificilmente abandonarão o controle de suas empresas em operações que envolvem fusões e/ou aquisições.

\section{Procedimentos metodológicos}

Neste estudo, uma pesquisa descritiva foi conduzida por meio de análise documental e abordagem quantitativa. A população compreendeu todas as empresas listadas em todos os setores da BM\&FBovespa, no período de 2007 a 2012. Empresas do setor financeiro foram excluídas em função de peculiaridades do setor, assim como foi procedido nas pesquisas de Caprio, Croci\& Del Giudice (2011), Shim \& Okamuro (2011), André, Ben -Amar \& Saadi (2012), Bouzgarrou \& Navatte (2013).
Para identificar as empresas posicionadas em operações de fusões e aquisições foram consultados os Formulários de Referência, na Seção 6.5 - Principais eventos societários. Esta seção é utilizada pelas empresas para descrever os principais eventos societários, como incorporações, fusões, cisões, incorporações de ações, alienações e aquisições de controle societário, aquisições e alienações de ativos importantes. Também foi consultada a seção 6.3 - Breve histórico dos Formulários de Referência e Informações Relevantes, já que algumas empresas divulgaram as informações sobre fusões e aquisições apenas nesses dois relatórios.

As análises ocorreram individualmente, em cada um destes três formulários, em cada um dos seis anos, para cada uma das empresas listadas na BM\&FBovespa. Após estas análises, foram identificadas 384 operações. No entanto, algumas empresas foram excluídas por não possuírem os dados necessários para todas as variáveis da pesquisa. Assim, a amostra final foi composta por 338 empresas posicionadas em operações de fusões e aquisições.

Para identificar o "posicionamento" das empresas em fusões e aquisições utilizou-se uma metodologia similar a de Caprio, Croci \& Del Giudice (2011). Criou-se uma variável categórica denominada de posicionamento com as seguintes categorias: 1 = Posicionamento ativo como adquirente; $0=$ Posicionamento passivo como adquirida. Para considerar uma empresa posicionada em operações de fusões ou aquisições, foram observados os dois critérios adotados no estudo de Caprio, Croci \& Del Giudice (2011): i) uma empresa foi considerada posicionada somente quando o negócio estava concluído no ano t; ii) foi verificado se o valor da operação era, no mínimo, de um milhão de reais. Assim como no estudo de André, Ben -Amar \& Saadi (2012), para as empresas envolvidas em mais de uma fusão ou aquisição no mesmo ano, foi considerada apenas a primeira fusão ou aquisição.

As variáveis de estrutura de propriedade são apresentadas no Quadro 1, com as respectivas variáveis, subvariáveis, métricas e autores de base.

Para identificar o tipo de estrutura de propriedade criou-se uma variável categórica denominada de "acionista controlador (AC)", que recebeu valor " 1 " 
nos casos em que o último acionista controlador era uma família ou um indivíduo (em termos de direitos de voto), com participação mínima de $10 \%$, assim como no estudo de La Porta, Lopez-de-Silanes \& Shleifer (1999), e valor "0" caso contrário.

Na identificação da concentração acionária foi considerada a soma dos percentuais de ações ordinárias $(\mathrm{ON})$, do percentual total de ações $(\mathrm{ON}+\mathrm{PN})$ e dos excessos de direito de voto do controlador. Nesse caso, quanto maior o percentual de ações em posse dos controlado- res, maior a concentração acionária. Seguiram-se os critérios adotados nos estudos de La Porta, Lopez-deSilanes \& Shleifer (1999), Claessens, Djankov \& Lang (2000), Faccio \& Lang (2002), Gugler, Ivanova \& Zechner (2014), Leung, Richardson \& Jaggi (2014).

No Quadro 2 evidenciam-se as métricas utilizadas para caracterizar a gestão (tipo, nível de aversão ao risco empresarial e desempenho) das empresas posicionadas em operações de fusões e aquisições.

Quadro 1. Constructo da pesquisa para as variáveis de estrutura de propriedade

\begin{tabular}{|c|c|c|c|}
\hline Variáveis & Subvariáveis & Métricas & Autores de base \\
\hline $\begin{array}{l}\text { Tipo de Estrutura de } \\
\text { propriedade }\end{array}$ & Acionista controlador (AC) & $\begin{array}{l}\text { AC: } \\
\text { Familiar }=1 \\
\text { Não familiar }=0\end{array}$ & La Porta, Lopez-de-Silanes \& Shleifer (1999). \\
\hline \multirow{3}{*}{$\begin{array}{l}\text { Concentração acionária do } \\
\text { último acionista } \\
\text { controlador }\end{array}$} & $\begin{array}{l}\text { Concentração de direitos de } \\
\text { voto (C_DV) }\end{array}$ & $\begin{array}{l}\text { C_DV = Percentual de ações } \\
\text { ordinárias (ON) }\end{array}$ & \multirow{3}{*}{$\begin{array}{l}\text { La Porta, Lopez-de-Silanes \& Shleifer (1999), } \\
\text { Claessens, Djankov \& Lang (2000), Faccio } \\
\text { \& Lang (2002), Gugler, Ivanova \& Zechner } \\
\text { (2014), Leung, Richardson \& Jaggi (2014). }\end{array}$} \\
\hline & $\begin{array}{l}\text { Concentração de direitos sobre } \\
\text { o fluxo de caixa (C_DFC) }\end{array}$ & $\begin{array}{l}\text { C_DFC = Percentual total de ações } \\
(\overline{O N}+\mathrm{PN})\end{array}$ & \\
\hline & $\begin{array}{l}\text { Concentração do excesso de } \\
\text { direitos de voto (C_EDV) }\end{array}$ & $\begin{array}{l}\text { C_EDV =Percentual de ações ordinárias } \\
\text { Percentual total de ações }\end{array}$ & \\
\hline
\end{tabular}

Fonte: Elaboração própria.

Quadro 2. Constructo da pesquisa para as variáveis de gestão

\begin{tabular}{|c|c|c|c|}
\hline Variáveis & Subvariáveis & Métricas & Autores de base \\
\hline \multirow{3}{*}{ Tipo de Gestão } & Diretor Presidente (Dir_Pres) & $\begin{array}{l}\text { Dir_Pres: Familiar }=1 \text { / Não } \\
\text { familiar }=0\end{array}$ & \multirow{3}{*}{$\begin{array}{l}\text { Villalonga \& Amit (2006); Miller et al. (2007); } \\
\text { Andres (2008); Block, Jaskiewicz \& Miller (2011); } \\
\text { Bouzgarrou \& Navatte (2013). }\end{array}$} \\
\hline & $\begin{array}{l}\text { Presidente do Conselho de Adminis- } \\
\text { tração (Pres_CA) }\end{array}$ & $\begin{array}{l}\text { Pres_CA: Familiar = } 1 \text { Não } \\
\text { familiar }=0\end{array}$ & \\
\hline & \begin{tabular}{|l|} 
Diretor Presidente e Presidente do Conse- \\
Iho de Administração (DirPres_PresCA) \\
\end{tabular} & $\begin{array}{l}\text { DirPres_PresCA: Familiar }=1 \\
\text { Não familiar }=0\end{array}$ & \\
\hline \multirow{4}{*}{$\begin{array}{l}\text { Nível de aversão } \\
\text { ao risco } \\
\text { empresarial }\end{array}$} & Variação do ROA (V_ROA) & $\begin{array}{l}\text { V_ROA = Coeficiente de } \\
\text { variação do ROA }\end{array}$ & \multirow{2}{*}{$\begin{array}{l}\text { Faccio, Marchica \& Mura (2011); Huybrechts, } \\
\text { Voordeckers \& Lybaert (2012). }\end{array}$} \\
\hline & Variação do ROE (V_ROE) & $\begin{array}{l}\text { V_ROE }=\text { Coeficiente de } \\
\text { variação do ROE }\end{array}$ & \\
\hline & Investimento em P\&D (I_P\&D) & \begin{tabular}{|l|} 
I_P\&D = Gastos com P\&D \\
Ativo total \\
\end{tabular} & $\begin{array}{l}\text { Anderson, Duru \& Reeb (2012); Bianco et al. (2013); } \\
\text { Su \& Lee (2013). }\end{array}$ \\
\hline & Grau de alavancagem financeira (GAF) & $\begin{array}{l}\text { GAF }=\text { P.C. + P.N.C. } \\
\text { Ativo Total } \\
\end{array}$ & $\begin{array}{l}\text { McConaughy, Mattews \& Fialko (2001); Anderson \& } \\
\text { Reeb (2003b); Schmid (2013). }\end{array}$ \\
\hline Desempenho & $\begin{array}{l}\text { ROA } \\
Q \text { de Tobin } \\
\left(Q_{-} \text {Tob) }\right.\end{array}$ & $\begin{array}{l}\text { ROA = Lajir / Ativo Total } \\
Q \text { de Tobin = Vlr. de mercado } \\
\text { dos Ativos } \\
\text { Custo de repos. dos Ativos }\end{array}$ & $\begin{array}{l}\text { Anderson \& Reeb (2003a); Villalonga \& Amit (2006); } \\
\text { Miller et al. (2007); Andres (2008); Cai, Luo \& Wan } \\
\text { (2012). }\end{array}$ \\
\hline
\end{tabular}

Fonte: Elaboração própria. 
Para identificar o tipo de gestão adotou-se a metodologia de Villalonga \& Amit (2006), que investigaram a participação das famílias na diretoria executiva e no conselho de administração. Nota-se no Quadro 2, que foram criadas três variáveis dummy, que receberam valor " 1 " nos casos em que o "diretor presidente (Dir_Pres)", o "presidente do Conselho de Administração (Pres_CA)" e ainda quando o "Diretor Presidente e o Presidente do Conselho de Administração (DirPres_PresCA)" eram o fundador da empresa, ou então, um membro por sangue ou casamento, pertencente à família controladora, ou valor " 0 " caso contrário.

A análise da aversão ao risco empresarial da gestão foi realizada com quatro variáveis. Nas duas primeiras variáveis, "variação do ROA (V_ROA)" e "variação do ROE (V_ROE)", adotou-se a metodologia de Huybrechts, Voordeckers e Lybaert (2012), que consideraram a variação de desempenho dos últimos cinco anos. Assim, quanto menor for o coeficiente de variação do ROA e do ROE, entende-se que maior será a aversão ao risco empresarial.

Para a terceira variável, "Investimento em $\mathrm{P} \& \mathrm{D}$ (I_P\&D)", foi adotada a metodologia de Anderson, Duru \& Reeb (2012), que analisaram a proporção de gastos com P\&D em relação ao Ativo Total das companhias. Os autores basearam-se em estudos anteriores, tais como Anderson \& Reeb (2003a) e outros, para argumentar que investimentos em $\mathrm{P} \& \mathrm{D}$ estão associados com retornos mais incertos. Nesses casos, maior intensidade dos gastos em $\mathrm{P} \& \mathrm{D}$ pode indicar uma propensão do gestor para operações que envolvem riscos.

A quarta variável, "Grau de alavancagem financeira (GAF)", foi analisada com base em McConaughy, Mattews \& Fialko (2001). Esses autores basearamse em estudos anteriores, como os de Grossman \& Hart (1986) e Mishra \& McConaughy (1999), para argumentar que o endividamento poderia implicar em risco para as empresas e, portanto, o risco a que estão expostos os gestores. Assim, os gestores tenderiam a ajustar a estrutura de capital de acordo com suas preferências em relação ao risco. $\mathrm{O}$ entendimento é que quanto menor for o grau de alavancagem, maior será a aversão ao risco.
Para análise do desempenho das gestões utilizaramse duas medidas. Uma baseada na contabilidade, Retorno Sobre os Ativos (ROA), e outra medida baseada no mercado, $Q$ de Tobin. A escolha para estas medidas foi baseada principalmente no estudo de Anderson \& Reeb (2003a). Neste estudo, pela falta dos dados necessários para calcular o Q de Tobin, do mesmo modo que Anderson \& Reeb (2003a), adotou-se uma metodologia alternativa, em que o "valor de mercado" corresponde à soma do valor contábil do Exigível + valor de resgate das ações preferenciais + valor de mercado das ações ordinárias, e o "custo de reposição" foi substituído pelo valor dos Ativos Totais. Essa metodologia alternativa também foi utilizada por Villalonga \& Amit (2006), Miller et al. (2007), Andres (2008), e Cai, Luo \& Wan (2012).

A variável "posicionamento" foi classificada como dependente na regressão logística e as variáveis de estrutura de propriedade e de gestão foram classificadas como independentes, juntamente com as variáveis de controle especificadas no Quadro 3, já que se busca verificar a influência dessas variáveis no posicionamento das empresas em fusões e aquisições.

Observa-se no Quadro 3 que as variáveis de controle utilizadas foram o tamanho, idade da empresa, caixa disponível, governança corporativa, crescimento da empresa e o setor de atuação. Estas variáveis também podem influenciar no posicionamento em fusões e aquisições (Basu, Dimitrova \& Paeglis, 2009; Feito \& Menéndez, 2010; Miller, Le BretonMiller \& Lester, 2010; Caprio, Croci \& Del Giudice, 2011; Shim \& Okamuro, 2011; Bouzgarrou \& Navatte, 2013; Gonenc, Hermes \& Sinderen, 2013).

A regressão logística, segundo Hair Jr, Anderson, Tatham \& Black (2005: 34), "[...] é a técnica multivariada adequada quando a única variável dependente é dicotômica". Que é o caso deste estudo, em que a variável dependente representa o posicionamento em fusões e aquisições, com atribuição de valor "0" para as empresas posicionadas como adquiridas $e$ " 1 " para aquelas posicionadas como adquirentes. Desta forma, buscou-se pela regressão logística verificar a associação da variável dependente/binária posicionamento com as diversas variáveis independentes e de controle. 


\section{Descrição e análise dos resultados}

Nesta seção, inicialmente evidencia-se (Quadro 4) o tipo de estrutura de propriedade das empresas posicionadas como adquirentes e das posicionadas como adquiridas nas operações de fusões e aquisições identificadas no período de 2007 a 2012.

Nota-se no Quadro 4, que o número total de empresas com estrutura de propriedade familiar envolvidas em fusões e aquisições é inferior ao número total de não familiares na amostra pesquisada. Todavia, ao se analisar o percentual de empresas adquirentes que possuem estrutura de propriedade familiar (86\%), verifica-se que este é bastante su- perior ao percentual de empresas adquirentes não familiar (62\%). Quando se analisa o percentual de empresas adquiridas familiares (14\%), percebe-se que é consideravelmente inferior ao número de empresas adquiridas não familiares (38\%).

Estes resultados confirmam os argumentos de Miller, Le Breton-Miller \& Lester (2010), Caprio, Croci \& Del Guidice (2011), Shim \& Okamuro (2011), e Bouzgarrou \& Navatte (2013), de que empresas familiares tendem a evitar o envolvimento em operações de fusões ou aquisições, mas, quando se envolvem, assumem uma posição ativa, como adquirentes.

Quadro 3. Variáveis de controle da pesquisa

\begin{tabular}{|l|l|l|}
\hline \multicolumn{1}{|c|}{ Variável } & \multicolumn{1}{|c|}{ Métrica } & \multicolumn{1}{c|}{ Autores de base } \\
\hline $\begin{array}{l}\text { Tamanho da empresa } \\
\text { (LogTam) }\end{array}$ & $\begin{array}{l}\text { Logaritmo natural do valor contábil dos ativos totais } \\
\text { da empresa }\end{array}$ & $\begin{array}{l}\text { Miller, Le Breton-Miller \& Lester (2010); Caprio, Croci \& Del Giudice } \\
\text { (2011); Shim \& Okamuro (2011); Gonenc, Hermes \& Sinderen } \\
\text { (2013). }\end{array}$ \\
\hline $\begin{array}{l}\text { Idade da empresa } \\
\text { (Idade Cia) }\end{array}$ & $\begin{array}{l}\text { Idade da empresa, medida pelo número de anos deco- } \\
\text { rridos desde a data de fundação constante no registro } \\
\text { da CVM }\end{array}$ & $\begin{array}{l}\text { Basu, Dimitrova \& Paeglis (2009); Shim \& Okamuro (2011); Go- } \\
\text { nenc, Hermes \& Sinderen (2013). }\end{array}$ \\
\hline $\begin{array}{l}\text { Caixa disponível } \\
\text { (Caixa_Disp) }\end{array}$ & $\begin{array}{l}\text { (Caixa e equivalentes de caixa + valores a receber de } \\
\text { curto prazo) / Ativo total }\end{array}$ & $\begin{array}{l}\text { Feito \& Menéndez (2010); Miller, Le Breton-Miller \& Lester (2010); } \\
\text { Caprio, Croci \& Del Giudice (2011); Shim \& Okamuro (2011); Go- } \\
\text { nenc, Hermes \& Sinderen (2013). }\end{array}$ \\
\hline $\begin{array}{l}\text { Governança corporativa } \\
\text { (N_GC) }\end{array}$ & $\begin{array}{l}\text { Nível diferenciado de governança corporativa da } \\
\text { BM\&FBovespa: Sim = 1 / Não = 0 }\end{array}$ & $\begin{array}{l}\text { Miller, Le Breton-Miller \& Lester (2010); Caprio, Croci \& Del Giudice } \\
\text { (2011); Shim \& Okamuro (2011). }\end{array}$ \\
\hline $\begin{array}{l}\text { Crescimento da empresa } \\
\text { (T_Crescim) }\end{array}$ & Taxa de crescimento dos ativos & $\begin{array}{l}\text { Feito \& Menéndez (2010); Caprio, Croci \& Del Giudice (2011); } \\
\text { Shim \& Okamuro (2011); Bouzgarrou \& Navatte (2013). }\end{array}$ \\
\hline Setor de atuação & Variáveis categóricas: 9 Setores da BM\&FBovespa & $\begin{array}{l}\text { Basu, Dimitrova \& Paeglis (2009); Miller, Le Breton-Miller \& Lester } \\
\text { (2010). }\end{array}$ \\
\hline
\end{tabular}

Fonte: Elaboração própria.

Quadro 4. Tipo de estrutura de propriedade das empresas

\begin{tabular}{|l|c|c|c|c|c|c|}
\hline \multicolumn{1}{|c|}{ Tipo de estrutura } & Amostra & $\%$ & Adquirentes & $\%$ & Adquiridas & $\%$ \\
\hline Familiares & 138 & 41 & 119 & 86 & 19 & 14 \\
\hline Não familiares & 200 & 59 & 125 & 62 & 75 & 38 \\
\hline Totais & 338 & 100 & 244 & 72 & 94 & 28 \\
\hline
\end{tabular}

Fonte: Dados da pesquisa. 
Na sequência, apresentam-se os resultados oriundos da regressão logística, para verificar a influência da estrutura de propriedade familiar no posicionamento como empresa adquirente ou adquirida em fusões e aquisições. No Quadro 5, demonstra-se como seriam classificadas as empresas caso o modelo se deixasse guiar apenas em função dos enquadramentos observados.

Verifica-se no Quadro 5 que a amostra composta por 244 empresas adquirentes e 94 empresas adquiridas teria uma pré-classificação em que todas as empresas estariam classificadas como adquirentes. Conforme a lógica de análise descrita por Corrar, Paulo \& Dias Filho (2007), indica que o modelo iria classificar corretamente as empresas adquirentes, mas incorretamente aquelas que foram adquiridas.
Nessa pesquisa, o percentual geral de acertos nas classificações foi de 71\%. Essa análise, segundo Corrar, Paulo \& Dias Filho (2007), serve como referência para avaliar a eficácia do modelo a partir do momento que ele passa a operar com todas as variáveis independentes. Assim, espera-se que tal percentual se eleve após a inclusão dessas variáveis.

No Quadro 6, apresentam-se os testes Step, Block e Model, Hosmer e Lemeshow, e os indicadores -2LL, Cox-Snell R ${ }^{2}$ e Nagelkerke, que possibilitam analisar, após a inclusão das variáveis independentes, se o modelo pode ser considerado capaz de realizar as predições com a acurácia desejada.

Quadro 5. Classificação anterior à análise da regressão que verifica a influência da estrutura de propriedade familiar no posicionamento como adquirente ou adquirida

\begin{tabular}{|c|c|c|c|c|c|}
\hline \multicolumn{6}{|c|}{ Quadro de classificação $(a, b)$} \\
\hline \multirow{2}{*}{\multicolumn{3}{|c|}{ Observado }} & \multicolumn{3}{|c|}{ Previsto } \\
\hline & & & \multicolumn{2}{|c|}{ Posicionamento } & \multirow{2}{*}{ Percentagem correta } \\
\hline & & & Adquirida & Adquirente & \\
\hline \multirow{3}{*}{ Step 0} & \multirow{2}{*}{ Posicionamento } & Adquirida & 0 & 94 & 0 \\
\hline & & Adquirente & 0 & 244 & 100 \\
\hline & Percentagem geral & & & & 71 \\
\hline
\end{tabular}

Fonte: Dados da pesquisa.

Quadro 6. Testes para validação do modelo da regressão logística da influência da estrutura de propriedade familiar no posicionamento como adquirente ou adquirida

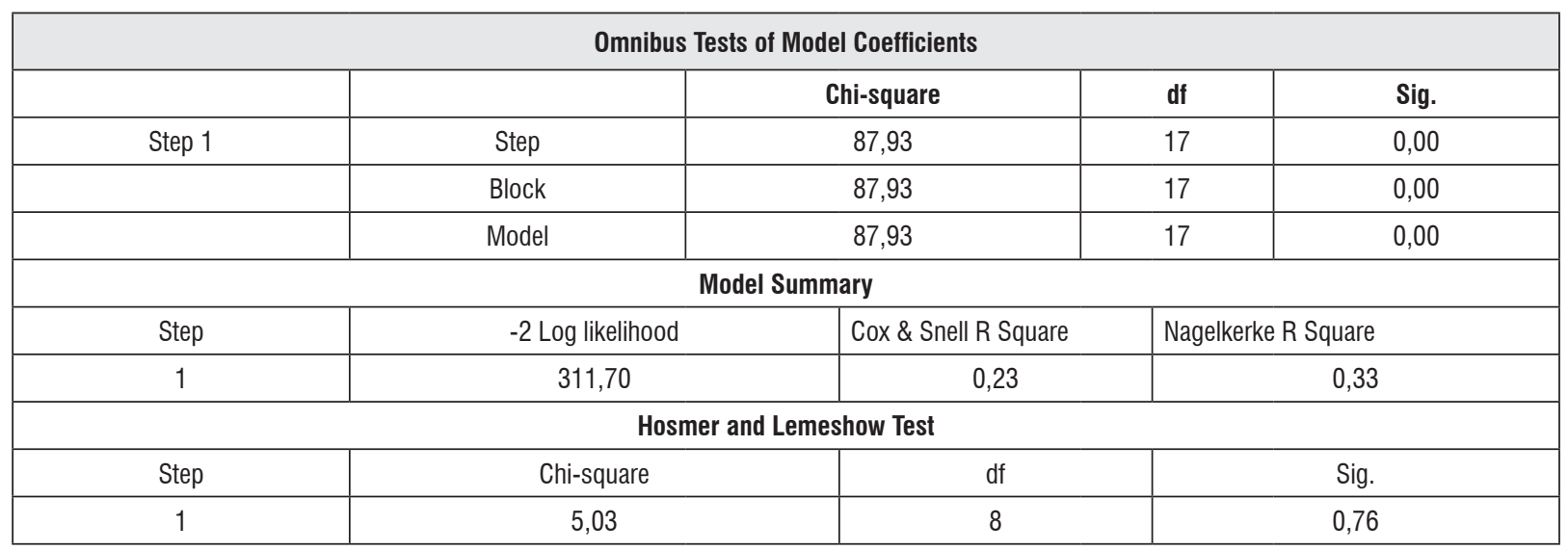

Fonte: Dados da pesquisa. 
Os testes Step, Block e Model objetivam demonstrar a capacidade preditiva do modelo. De acordo com o Quadro 6, o resultado foi de 87,93, significativo estatisticamente a um nível de 0,00 , confirmando que as variáveis independentes contribuem para melhorar a qualidade das predições. Verifica-se ainda um valor para -2Log likelihood correspondente a 311,70 , que indica um bom ajuste.

Os testes Cox e Snell e Nagelkerke são considerados Pseudos-R-Quadrado e se assemelham ao coeficiente de determinação $\mathrm{R}^{2}$ utilizado no modelo linear, conforme Corrar, Paulo \& Dias Filho (2007). O Cox e Snell, nessa pesquisa, indica que aproximadamente $23 \%$ das variações ocorridas no log da razão da variável dependente (adquirentes ou adquiridas) são explicadas pelo conjunto das variáveis independentes. O Nagelkerke, de acordo com Corrar, Paulo \& Dias Filho (2007), trata-se de uma versão adaptada do Cox e Snell que fornece resultados entre zero e um e, nessa pesquisa, indica que o modelo é capaz de explicar em torno de 33\% das variações registradas na variável dependente.

Estes percentuais preditivos são superiores aos apresentados no estudo de Shim \& Okamuro (2011), que utilizaram-se de regressões logísticas para analisar questões similares, em que o indicador Nagelkerke ficou entre 10\% e 15\%, e superior ao Negelkerke das regressões da pesquisa de Caprio, Croci \& Del Giudice (2011), que variou entre 9\% e $14 \%$.

Por último, o teste Hosmer e Lemesshow, que visa, segundo Corrar, Paulo \& Dias Filho (2007), testar a hipótese de que não ocorrem diferenças significativas entre o que foi predito e o observado pelo modelo, resultou em um valor de 5,03 e não possui significância estatística $(\mathrm{Sig}=0,76)$. Esse resultado indica que os valores preditos não foram significativamente diferentes dos observados, portanto, mais um sinal de que o modelo é adequado para verificar a influência da estrutura de propriedade familiar no posicionamento das empresas da amostra.

No Quadro 7, evidenciam-se as respectivas variáveis independentes com seus scores e níveis de significância.
Quadro 7. Variáveis independentes da regressão logística da influência da estrutura de propriedade familiar no posicionamento como adquirente ou adquirida

\begin{tabular}{|l|c|c|c|c|c|}
\hline \multicolumn{7}{|c|}{ Variáveis da equação } \\
\hline \multicolumn{1}{|c|}{ Variáveis } & B & S.E. & Wald & df & Sig. \\
\hline AC(1) & 1,31 & 0,36 & 13,49 & 1,00 & $\mathbf{0 , 0 0}$ \\
\hline C_DV & 1,04 & 1,69 & 2,03 & 1,00 & $\mathbf{0 , 0 5}$ \\
\hline C_DFC & 0,11 & 1,99 & 0,00 & 1,00 & 0,16 \\
\hline C_EDV & $-0,09$ & 0,44 & 0,04 & 1,00 & 0,77 \\
\hline LogTam & 0,22 & 0,05 & 22,39 & 1,00 & $\mathbf{0 , 0 0}$ \\
\hline IdadeCia & 0,00 & 0,01 & 0,31 & 1,00 & 0,58 \\
\hline Caixa_Disp & 2,89 & 0,91 & 10,09 & 1,00 & $\mathbf{0 , 0 0}$ \\
\hline N_GC(1) & 0,54 & 0,34 & 2,54 & 1,00 & $\mathbf{0 , 0 9}$ \\
\hline T_Crescim & 0,00 & 0,00 & 0,27 & 1,00 & 0,60 \\
\hline BensInd(1) & 0,58 & 0,64 & 0,84 & 1,00 & 0,36 \\
\hline ConstrTransp(1) & 0,76 & 0,55 & 1,91 & 1,00 & $\mathbf{0 , 0 9}$ \\
\hline ConsCicl(1) & 0,62 & 0,62 & 1,00 & 1,00 & $\mathbf{0 , 0 3}$ \\
\hline ConcNaoCicl(1) & $-0,15$ & 0,52 & 0,09 & 1,00 & 0,77 \\
\hline MatBas(1) & $-0,89$ & 0,57 & 2,43 & 1,00 & $\mathbf{0 , 0 2}$ \\
\hline PetrolGasBio(1) & 1,02 & 1,31 & 0,60 & 1,00 & 0,44 \\
\hline TecInf(1) & 1,25 & 1,31 & 0,90 & 1,00 & 0,34 \\
\hline Telecom(1) & $-0,71$ & 0,66 & 1,17 & 1,00 & $\mathbf{0 , 0 3}$ \\
\hline UtilPubl(1) & 0,58 & 0,64 & 0,84 & 1,00 & 0,36 \\
\hline (Constante) & 3,12 & 3,75 & 0,69 & 1,00 & 0,41 \\
\hline
\end{tabular}

Fonte: Dados da pesquisa.

Observa-se no Quadro 7 que, entre as variáveis relacionadas a estrutura de propriedade, AC, C_DV, C_DFC e C_EDV, apenas a variável AC, que capta o tipo de estrutura de propriedade, e a variável C_DV, que se refere a concentração de votos, apresentaram coeficientes estatisticamente significantes. Os coeficientes positivos indicam que a estrutura de propriedade familiar e a concentração de direitos de voto influenciam para o posicionamento ativo das empresas, como adquirentes.

Denota-se, com base nesses resultados, que não é somente a valorização do controle acionário que influencia para o posicionamento ativo como adquirente, mas, principalmente o tipo de controlador, visto que o coeficiente da variável AC $(1,31)$ foi superior ao coeficiente da variável C_DV $(1,04)$. Esses resultados confirmam os argumentos de Miller, Le Breton-Miller \& Lester (2010), Shim \& Okamuro 
(2011), Caprio, Croci \& Del Guidice (2011) e Bouzgarrou \& Navatte (2013), de que, no envolvimento em operações de fusões e aquisições, as empresas familiares tendem a assumir uma posição ativa, ou seja, como adquirentes.

Destaca-se ainda no Quadro 7, que a variável C_EDV, que se refere aos excessos de direitos de votos dos controladores, apesar de não ser estatisticamente significante, apresentou um coeficiente negativo $(-0,09)$, sugerindo que quanto maior for a divergência entre os direitos de voto e os direitos sobre o fluxo de caixa, maior será a probabilidade de que as empresas se posicionem de forma passiva como adquiridas em fusões e aquisições. Uma possível justificativa para esse resultado, conforme Holmen \& Nivorozhkin (2007) e Caprio, Croci \& Del Guidice (2011) é que os excessos de direitos de voto refletem menor valorização pelo controle acionário, maior tendência a conflitos de agência e maior possibilidade de envolvimento em fusões ou aquisições por fins oportunistas.

As variáveis de controle LogTam, Caixa_Disp e N_GC revelaram-se estatisticamente significantes. Portanto, confirmou-se que empresas maiores (LogTam), em razão dos recursos financeiros e não financeiros superiores, tendem a assumir um posicionamento ativo, como adquirentes. As empresas que possuem maior disponibilidade de caixa (Caixa_Disp) estarão mais propensas a se envolverem em operações de fusões $e$ aquisições de forma ativa. Além disso, melhores práticas de governança corporativa (N_GC) contribuem para um posicionamento ativo, como adquirente, no caso de operações de fusões e aquisições.

As variáveis IdadeCia e T_Crescim, além de não possuírem significância estatística, apresentaram coeficientes próximos a zero. Nesse caso, sinalizando que um maior tempo de atuação no mercado e níveis de crescimento superiores não influenciam para o posicionamento ativo como adquirente. No caso do tempo de atuação, infere-se que o tempo pode aumentar o conservadorismo e a resistência a mudanças, visto que o coeficiente próximo a zero demonstra que não há impacto para o posicionamento ativo e nem para um posicionamento passivo. No caso da taxa de crescimento, o coeficiente, também próximo a zero, evidencia que empresas para manterem o índice de crescimento, podem se posicionar como adquirentes ou como adquiridas.

Entre as variáveis categóricas que capturam o efeito dos setores, houve significância estatística para as variáveis relacionadas ao setor de construção $e$ transporte $(0,09)$, consumo cíclico $(0,03)$, materiais básicos $(0,02)$ e para o setor de telecomunicações $(0,03)$. O setor de construção e transporte e o setor de consumo cíclico apresentaram coeficientes positivos de 0,76 e 0,62, respectivamente, evidenciando que as empresas desses setores tendem a se posicionar como adquirentes em fusões e aquisições. De modo contrário, o setor de materiais básicos e o setor de telecomunicações apresentaram coeficientes negativos de $-0,89$ e $-0,71$, respectivamente, apontando influência para um posicionamento passivo das empresas, como adquiridas. Os demais setores não possuem coeficientes estatisticamente significantes.

No Quadro 8, demonstra-se o percentual de acertos nas classificações após a inclusão das variáveis independentes.

Nota-se no Quadro 8, que após a inclusão das variáveis independentes, o percentual de acerto do modelo, que antes era de 71\% (apresentado no Quadro 5), elevou-se para $81 \%$. Ao analisar as 94 empresas adquiridas, nota-se que 49\% estariam classificadas corretamente. Em relação as 244 empresas adquirentes, verifica-se que o percentual de acertos após a inclusão das variáveis independentes é ainda superior, pois equivale a $93 \%$.

Portanto, ao considerar esses resultados, é possível afirmar estatisticamente que a estrutura de propriedade familiar influencia para o posicionamento como adquirente entre as companhias que compõem a amostra de pesquisa, em conformidade com os estudos de Miller, Le Breton-Miller \& Lester (2010), Shim \& Okamuro (2011), Caprio, Croci \& Del Guidice (2011), e Bouzgarrou \& Navatte (2013).

Na sequência faz-se a análise da influência da gestão familiar no posicionamento. Inicialmente, no Quadro 9, evidencia-se o tipo de gestão das empresas posicionadas como adquirentes e daquelas posicionadas como adquiridas. 
Nota-se no Quadro 9, que o número de empresas com gestão familiar envolvidas em operações de fusões $e$ aquisições é bastante inferior ao número de não familiares. Entretanto, o percentual de empresas com gestão familiar posicionadas como adquirentes supera o percentual de empresas com gestão não familiar. Além disso, o percentual de empresas posicionadas como adquiridas também é consideravelmente inferior.

No Painel A, verifica-se que dentre as 79 empresas com diretor presidente familiar, $89 \%$ delas posicionaram-se como adquirentes e apenas $11 \%$ como adquiridas. Por outro lado, quando o diretor presidente não é familiar, apenas $67 \%$ posicionaram-se como adquirentes e $33 \%$ como adquiridas. No Painel B, nota-se que dentre as 110 empresas com o presidente do conselho de administração familiar, 90\% delas posicionaram-se como adquirentes e apenas 10\% como adquiridas. Por outro lado, quando o presidente do conselho não é familiar, apenas $64 \%$ dessas posicionaram-se como adquirentes e $36 \%$ como adquiridas. No Painel C, observa-se que dentre as 67 empresas com o diretor presidente e o presidente do conselho de administração familiar, 90\% delas posicionaramse como adquirentes e apenas 10\% como adquiridas. Por outro lado, quando estes cargos são ocupados por indivíduos não familiares, apenas $68 \%$ posicionaram-se como adquirentes e 32\% como adquiridas.

De modo geral, os resultados corroboram os argumentos das pesquisas de Tsai, Kuo \& Hung (2009), Miller, Le Breton-Miller \& Lester (2010), Caprio, Croci \& Del Giudice (2011), Gómez-Mejía et al. (2011), Shim \& Okamuro (2011), e Bouzgarrou \& Navatte (2013), de que empresas familiares tendem a evitar o envolvimento em operações de fusões ou aquisições, mas, quando se envolvem, assumem uma posição ativa, ou seja, como adquirentes.

Quadro 8. Classificação final da análise da regressão da influência da estrutura de propriedade familiar no posicionamento como adquirente ou adquirida

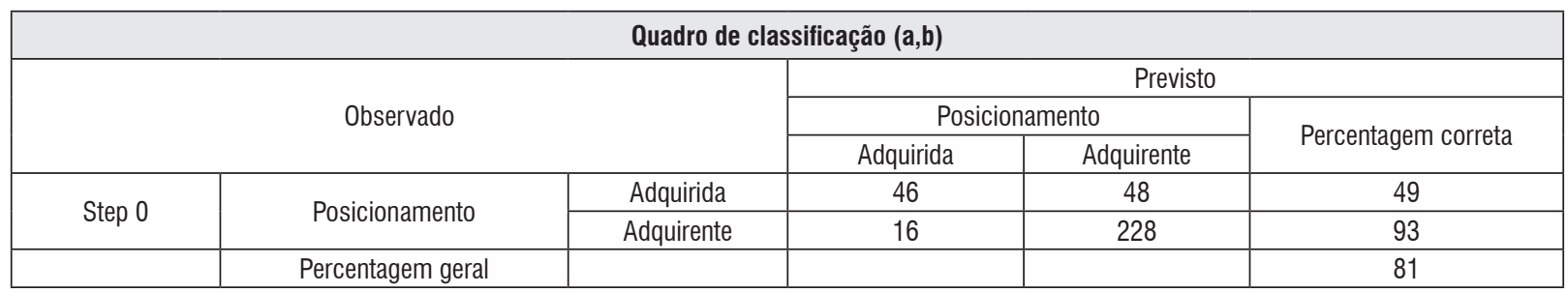

Fonte: Dados da pesquisa.

Quadro 9. Tipo de gestão das empresas posicionadas como adquirentes e adquiridas

\begin{tabular}{|c|c|c|c|c|c|c|}
\hline \multicolumn{7}{|c|}{ Painel A-Diretor Presidente } \\
\hline Diretor Presidente & Total & $\%$ & Adquirentes & $\%$ & Adquiridas & $\%$ \\
\hline Familiar & 79 & 23 & 70 & 89 & 9 & 11 \\
\hline Não familiar & 259 & 77 & 174 & 67 & 85 & 33 \\
\hline Total de empresas & 338 & 100 & 244 & 72 & 94 & 28 \\
\hline \multicolumn{7}{|c|}{ Painel B-Presidente do Conselho de Administração } \\
\hline Presidente do C. A. & Total & $\%$ & Adquirentes & $\%$ & Adquiridas & $\%$ \\
\hline Familiares & 110 & 33 & 99 & 90 & 11 & 10 \\
\hline Não familiares & 228 & 67 & 145 & 64 & 83 & 36 \\
\hline Total de empresas & 338 & 100 & 244 & 72 & 94 & 28 \\
\hline \multicolumn{7}{|c|}{ Painel C-Diretor Presidente e Presidente do Conselho de Administração } \\
\hline Dir. Pres. e Pres. C.A. & Total & $\%$ & Adquirentes & $\%$ & Adquiridas & $\%$ \\
\hline Familiares & 67 & 20 & 60 & 90 & 7 & 10 \\
\hline Não familiares & 271 & 80 & 184 & 68 & 87 & 32 \\
\hline Total de empresas & 338 & 100 & 244 & 72 & 94 & 28 \\
\hline
\end{tabular}

Fonte: Dados da pesquisa. 
A seguir, apresentam-se os resultados oriundos da regressão logística, que permite averiguar a influência da gestão familiar no posicionamento como adquirente ou adquirida. O primeiro passo é demonstrar, conforme Quadro 10, como seriam classificadas as empresas caso o modelo se deixasse guiar apenas em função dos enquadramentos observados.

Observa-se no Quadro 10, que a amostra composta por 244 empresas adquirentes e 94 empresas adquiridas teria uma pré-classificação em que todas as empresas estariam classificadas como adquirentes. Nessa pesquisa, o percentual geral de acertos nas classificações seria de $72 \%$. Espera-se que tal percentual se eleve após a inclusão das variáveis independentes.
No Quadro 11, apresentam-se os testes Step, Block e Model, Hosmer \& Lemeshow, e os indicadores -2LL, Cox-Snell $\mathrm{R}^{2}$ e Nagelkerke, que possibilitam analisar, após a inclusão das variáveis independentes, se o modelo pode ser considerado capaz de realizar as predições com a acurácia desejada.

Observa-se no Quadro 11, que os testes Step, Block e Model, que demonstram a capacidade preditiva do modelo, apresentaram um indicador equivalente a 107,92, significativo estatisticamente a um nível de 0,00. Confirma-se, assim, que as variáveis independentes contribuem para melhorar a qualidade das predições.

Quadro 10. Classificação anterior à análise da regressão que verifica a influência da gestão familiar no posicionamento como adquirente ou adquirida

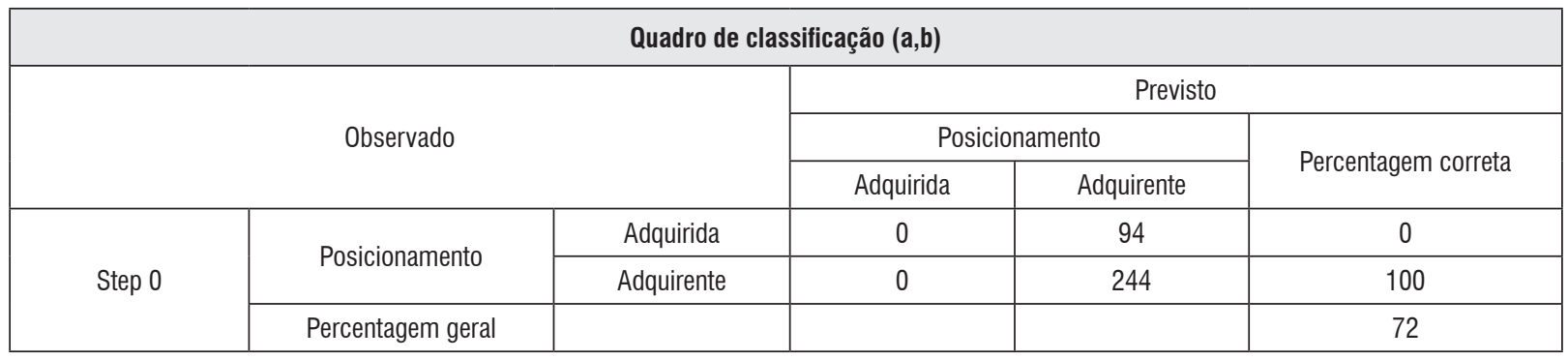

Fonte: Dados da pesquisa.

Quadro 11. Testes para validação do modelo da regressão logística da influência da gestão familiar no posicionamento como adquirente ou adquirida

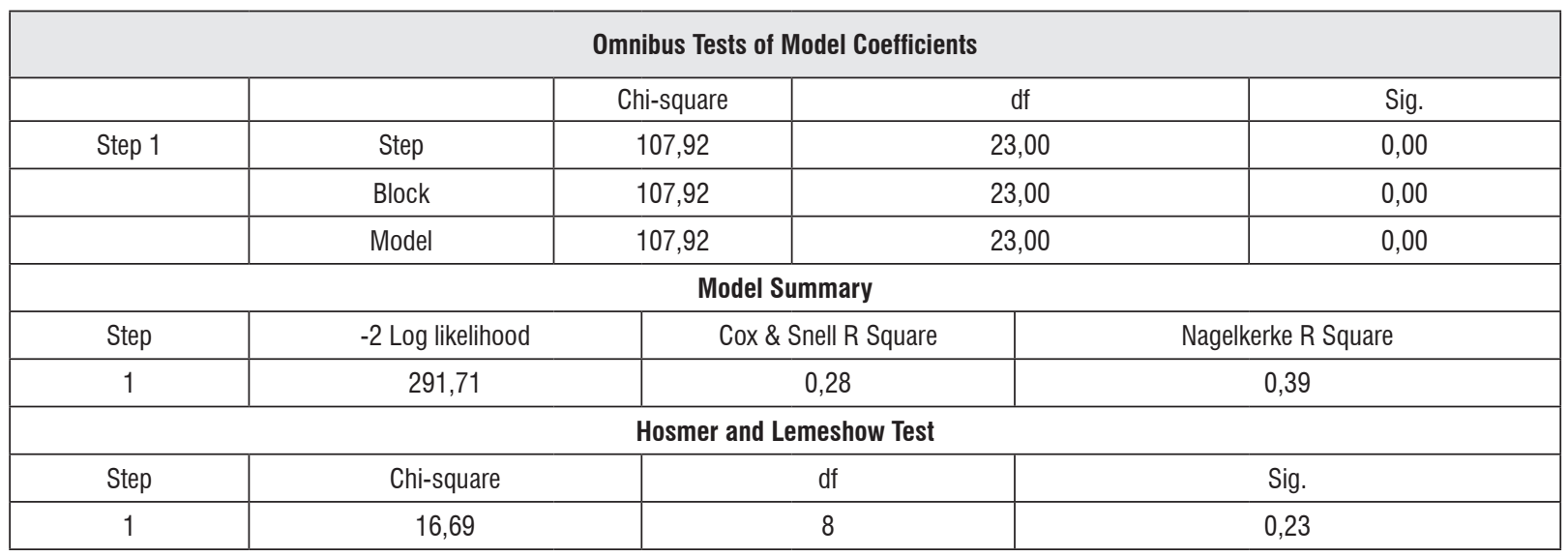

Fonte: Dados da pesquisa. 
O teste -2Log likelihood correspondente a 291,71 indica um bom ajuste. O teste Cox e Snell indicou que aproximadamente $28 \%$ das variações ocorridas no log da razão da variável dependente (adquirentes ou adquiridas) são explicadas pelo conjunto das variáveis independentes. O Nagelkerke indica que o modelo é capaz de explicar em torno de 39\% das variações registradas na variável dependente. Estes percentuais preditivos são superiores aos do estudo de Shim \& Okamuro (2011), em que o indicador Nagelkerke ficou entre 10\% e 15\%. Também foi superior ao $\mathrm{Ne}$ gelkerke das regressões da pesquisa de Caprio, Croci $\&$ Del Giudice (2011), que variou entre 9 e 14\%.

Por último, o teste Hosmer e Lemesshow resultou em um valor de 16,69 e não possui significância estatística ( $\mathrm{Sig}=0,23$ ), indicando que os valores preditos não foram significativamente diferentes dos observados, portanto, acredita-se que o modelo é adequado para verificar a influência da gestão familiar no posicionamento das empresas da amostra.

Nota-se no Quadro 12, que as três variáveis relacionadas ao tipo de gestão, Dir_Pres, Pres_CA e DirPres_PresCA, que captam a presença de um membro da família ocupando o cargo de diretor presidente, o cargo de presidente do conselho de administração, e ainda, quando os dois cargos estão sob domínio da família, respectivamente, revelaram-se estatisticamente significantes.

Denota-se, com base nesses resultados, que não é somente a aversão ao risco e um melhor desempenho que influenciam para que o posicionamento ocorra de forma ativa, como adquirente, mas, principalmente o tipo de gestão, ou seja, se familiar ou não familiar, visto que os coeficientes das variáveis relacionadas ao tipo de gestão $(0,57,1,43$ e 0,41) foram superiores aos coeficientes das variáveis de risco e desempenho.

Dentre as quatro variáveis utilizadas para analisar a aversão ao risco das gestões, observa-se no Quadro 12 , que as variáveis V_ROA, V_ROE e I_P\&D apresentaram coeficientes negativos, ou seja, indicando influência para um posicionamento passivo das empresas, como adquiridas. Maior variação do ROA, maior variação do $\mathrm{ROE}$ e maiores investimentos em $\mathrm{P} \& \mathrm{D}$ refletem um comportamento de risco das gestões. Nesse caso, os coeficientes negativos da regressão logística demonstram que maiores variações do ROA e do ROE e maiores investimentos em P\&D, ou seja, um maior comportamento de risco influencia para o posicionamento passivo das empresas, como adquiridas em operações de fusões e aquisições. Ressalta-se que o coeficiente da variável V_ROA não foi estatisticamente significante ( $\mathrm{Sig}=0,88)$, logo, o resultado associado a esta variável pode não ser confiável.

No Quadro 12, evidenciam-se as variáveis independentes com seus respectivos scores e níveis de significância.

Quadro 12. Variáveis independentes da regressão logística da influência da gestão familiar no posicionamento como adquirente ou adquirida

\begin{tabular}{|c|c|c|c|c|c|}
\hline \multicolumn{7}{|c|}{ Variáveis da equação } \\
\hline Variáveis & B & S.E. & Wald & df & Sig. \\
\hline Dir_Pres(1) & 0,57 & 0,29 & 1,07 & 1,00 & 0,06 \\
\hline Pres_CA(1) & 1,43 & 0,62 & 5,40 & 1,00 & 0,02 \\
\hline DirPres_PresCA(1) & 0,41 & 0,10 & 1,30 & 1,00 & 0,08 \\
\hline V_ROA & $-0,01$ & 0,04 & 0,02 & 1,00 & 0,88 \\
\hline V_ROE & $-0,18$ & 0,06 & 9,27 & 1,00 & 0,00 \\
\hline I_P\&D & $-0,31$ & 0,14 & 4,84 & 1,00 & 0,04 \\
\hline GAF & 0,30 & 0,15 & 4,17 & 1,00 & 0,04 \\
\hline ROA & 0,31 & 0,14 & 4,84 & 1,00 & 0,04 \\
\hline Qtob & 0,52 & 0,24 & 4,54 & 1,00 & 0,03 \\
\hline LogTam & 0,15 & 0,05 & 7,47 & 1,00 & 0,01 \\
\hline IdadeCia & 0,00 & 0,01 & 0,45 & 1,00 & 0,50 \\
\hline Caixa_Disp & 1,69 & 0,98 & 2,99 & 1,00 & 0,08 \\
\hline N_GC(1) & 0,84 & 0,38 & 5,01 & 1,00 & 0,03 \\
\hline T_Crescim & 0,00 & 0,00 & 0,17 & 1,00 & 0,68 \\
\hline BensInd(1) & 0,85 & 0,70 & 1,47 & 1,00 & 0,23 \\
\hline ConstrTransp(1) & 0,95 & 0,57 & 2,71 & 1,00 & 0,10 \\
\hline ConsCicl(1) & 0,98 & 0,58 & 2,91 & 1,00 & 0,09 \\
\hline ConcNaoCicl(1) & $-0,02$ & 0,57 & 0,00 & 1,00 & 0,98 \\
\hline MatBas(1) & $-1,47$ & 0,86 & 2,94 & 1,00 & 0,09 \\
\hline PetrolGasBio(1) & 0,24 & 1,71 & 0,02 & 1,00 & 0,89 \\
\hline TecInf(1) & $-0,18$ & 0,58 & 0,09 & 1,00 & 0,76 \\
\hline Telecom(1) & $-0,50$ & 0,25 & 4,05 & 1,00 & 0,04 \\
\hline (Constante) & $-4,52$ & 1,66 & 7,42 & 1,00 & 0,01 \\
\hline & & & & \\
\hline & & & \\
\hline
\end{tabular}

Fonte: Dados da pesquisa. 
Em relação a variável GAF, o coeficiente foi positivo $(0,30)$, apontando que maiores níveis de alavancagem financeira influenciam para o posicionamento ativo das empresas, como adquirentes. $\mathrm{O}$ grau de alavancagem financeira, quando elevado, reflete comportamento de risco da gestão. Neste caso, a alavancagem pode estar facilitando a obtenção de recursos financeiros para que as empresas se posicionem de forma ativa, como adquirentes.

Em relação as duas variáveis de desempenho, verifica-se que ambas foram estatisticamente significantes a um nível de significância de 0,05. Deste modo, infere-se que empresas que possuem Retorno Sobre o Ativo (ROA) e $\mathrm{Q}$ de Tobin superiores se posicionam como adquirentes em operações de fusões e aquisições.

Estes resultados confirmam os preceitos de Miller, Le Breton-Miller \& Lester (2010), de que famílias tendem a assumir uma posição ativa, como adquirentes, para que possam seguir com suas políticas de gestão. Também corroboram os argumentos de Tsai, Kuo \& Hung (2009), Miller, Le Breton-Miller \& Lester (2010), Caprio, Croci \& Del Giudice (2011), Gómez et al. (2011), Shim \& Okamuro (2011), e Bouzgarrou \& Navatte (2013), de que a aversão ao risco e o desempenho superior da gestão, principalmente quando são familiares, contribuem para um posicionamento ativo como adquirentes em fusões e aquisições.

As variáveis de controle LogTam, Caixa_Disp e N_GC revelaram-se estatisticamente significantes. Desse modo, empresas maiores (LogTam), em razão dos recursos financeiros e não financeiros su- periores, tendem a assumir um posicionamento ativo, como adquirentes. As empresas que possuem maiores disponibilidades de caixa (Caixa_Disp) estarão mais propensas a se envolverem em operações de fusões e aquisições de forma ativa. Além disso, melhores práticas de governança corporativa (N_GC) contribuem para um posicionamento ativo, como adquirentes. As variáveis IdadeCia e T_Crescim, além de não possuírem significância estatística, apresentaram coeficientes próximos a zero, sinalizando que maior tempo de atuação no mercado $e$ níveis de crescimento superiores não influenciam para o posicionamento ativo, como adquirentes.

Entre as variáveis categóricas que capturam o efeito dos setores, houve significância estatística para as variáveis relacionadas ao setor de construção $e$ transporte $(0,10)$, consumo cíclico $(0,09)$, materiais básicos $(0,09)$ e para o setor de telecomunicações $(0,04)$. Os demais setores não apresentaram coeficientes estatisticamente significantes.

No Quadro 13, demonstra-se o percentual de acertos nas classificações após a inclusão das variáveis independentes.

Nota-se no Quadro 13, após a inclusão das variáveis independentes, que o percentual de acerto do modelo, que antes era de 71\% (apresentado no Quadro 10), elevou-se para 83\%. Ao analisar as 94 empresas adquiridas, verifica-se que 51\% estariam classificadas corretamente. Em relação as 244 empresas adquirentes, verifica-se que o percentual de acertos após a inclusão das variáveis independentes é ainda superior, pois equivale a 95\%.

Quadro 13. Classificação final da análise da regressão da influência da gestão familiar no posicionamento como adquirente ou adquirida

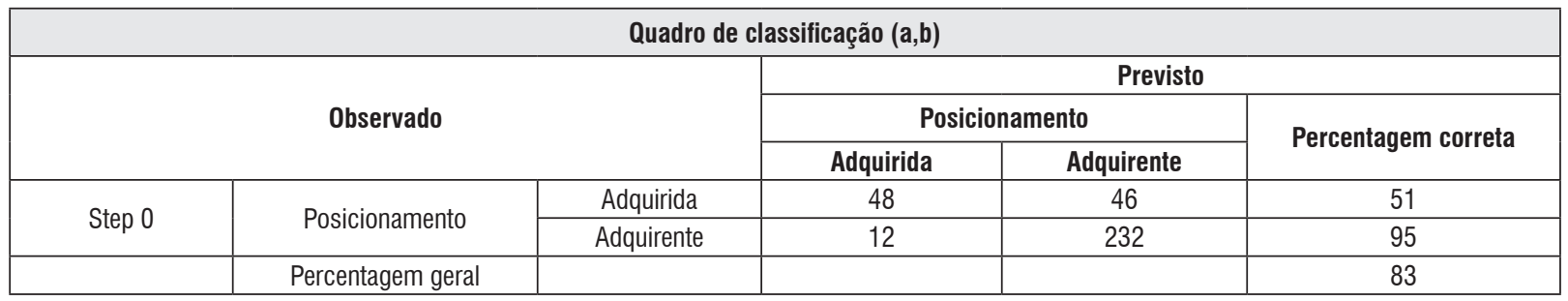

Fonte: Dados da pesquisa. 
Portanto, ao considerar estes resultados, é possível afirmar estatisticamente que a gestão familiar também influencia para o posicionamento como adquirente. Esses resultados estão alinhados com os estudos de Tsai, Kuo \& Hung (2009); Miller, Le Breton-Miller \& Lester (2010); Caprio, Croci \& Del Giudice (2011); Gómez et al. (2011); Shim \& Okamuro (2011); e Bouzgarrou \& Navatte (2013).

\section{Considerações Finais}

Este estudo verificou a influência da estrutura de propriedade e da gestão familiar no posicionamento em operações de fusões e aquisições de empresas listadas na BM\&FBovespa. Os resultados revelaram que o número total de empresas com estrutura de propriedade familiar envolvidas em operações de fusões e aquisições foi inferior ao número total de não familiares. No entanto, o percentual de empresas adquirentes com estrutura familiar foi superior ao de empresas adquirentes não familiares. Por sua vez, o percentual de empresas adquiridas familiares foi consideravelmente inferior ao de empresas adquiridas não familiares.

Na regressão logística, a estrutura de propriedade familiar e a concentração de direitos de voto apresentaram coeficientes positivos e estatisticamente significantes para o posicionamento como adquirente. Isso indica que não foi apenas a valorização do controle acionário que influenciou o posicionamento ativo como adquirente, mas, principalmente, o tipo de controlador (familiar). Esses resultados confirmam os argumentos de Miller, Le Breton-Miller \& Lester (2010); Caprio, Croci \& Del Guidice (2011); Shim \& Okamuro (2011); e Bouzgarrou \& Navatte (2013), de que as empresas com estrutura de propriedade familiar, em operações de fusões $e$ aquisições, tendem a assumir uma posição ativa, como adquirentes.

Portanto, nas empresas pesquisadas pode-se depreender que, de modo geral as famílias não abrem mão com facilidade do controle acionário das suas empresas quando se envolvem em fusões e aquisições. Ao contrário, há maior propensão das empresas que possuem estrutura de propriedade não familiar para o posicionamento passivo, como adqui- ridas, o que denota menor valorização pelo controle acionário, maior tendência a conflitos de agência $e$ maior possibilidade de envolvimento em fusões ou aquisições com fins oportunistas.

No tocante à influência da gestão familiar no posicionamento como empresa adquirente ou adquirida em fusões e aquisições, constatou-se que o número total de empresas com gestão familiar envolvidas em operações de fusões e aquisições foi inferior ao número total de não familiares. Entretanto, o percentual de empresas com gestão familiar posicionadas como adquirentes superou o percentual de empresas com gestão não familiar.

Os resultados da regressão logística revelaram que um membro da família ocupando o cargo de diretor presidente, o cargo de presidente do conselho de administração, ou ainda, quando os dois cargos estavam sob domínio da família, respectivamente, influenciavam a opção para o posicionamento ativo, ou seja, como adquirente em fusões e aquisições. Esses resultados coadunam com as constatações já destacadas no referencial teórico deste estudo.

Dentre as quatro variáveis consideradas para analisar a aversão ao risco da gestão, três apresentaram coeficientes negativos, o que indica que maior risco influencia a opção para o posicionamento passivo das empresas, como adquiridas em operações de fusões e aquisições. Uma das variáveis, o grau de alavancagem financeira, apresentou coeficiente positivo. O grau de alavancagem financeira, quando elevado, também representa comportamento de risco da gestão. Porém, neste caso, a alavancagem pode favorecer a obtenção de recursos financeiros para que as empresas se posicionem de forma ativa, como adquirentes. Em relação às duas variáveis de desempenho, ambas foram estatisticamente significantes e revelaram poder preditivo para o posicionamento como adquirente.

Os coeficientes mais elevados para as variáveis que captaram a presença das famílias nos cargos de gestão permitem inferir que não é apenas a aversão ao risco e o desempenho que influenciaram a opção para o posicionamento ativo como adquirente, mas, principalmente, o tipo de gestão, neste caso, a 
gestão familiar. Esses resultados confirmam os preceitos de Miller, Le Breton-Miller \& Lester (2010), de que a gestão familiar tende a assumir uma posição ativa, como adquirente, para que possa seguir com suas políticas de gestão. Os resultados também estão alinhados com os argumentos de Tsai, Kuo \& Hung (2009); Caprio, Croci \& Del Giudice (2011); Gómez et al. (2011); Shim \& Okamuro (2011); e Bouzgarrou \& Navatte (2013), de que maior envolvimento das famílias na empresa contribui para um posicionamento ativo, como adquirentes em operações de fusões e aquisições.

O tema tem merecido crescente atenção e provocado relevantes discussões no meio acadêmico, principalmente em âmbito internacional, com destaque para países com robustas bolsas de valores. Desse modo, os resultados da pesquisa realizada oferecem contribuições para os estudos teórico-empíricos relacionados, em especial, sobre os fatores que influenciam as famílias para o posicionamento como empresa adquirente ou adquirida em fusões e aquisições. Além disso, o estudo contribui para a literatura com evidências empíricas relativas ao cenário brasileiro, ainda carente de pesquisas no campo empírico em relação a esse tema.

Dadas as limitações deste estudo, recomenda-se para futuras pesquisas sobre o tema que, ao identificar o tipo de estrutura de propriedade, sejam considerados percentuais superiores para definir o tipo de estrutura de propriedade, como por exemplo, um percentual mínimo de $20 \%$, ou ainda um percentual mínimo de 50\%, assim como Leung, Richardson \& Jaggi (2014) e Steijvers \& Voordeckers (2009), respectivamente. Na identificação $e$ análise da gestão familiar, nesta pesquisa não se fez distinção entre fundadores e descendentes, mas em pesquisas futuras recomenda-se fazer tal distinção.

\section{Referências}

Andres, C. (2008). Large shareholders and firm performance: an empirical examination of founding-family ownership. Journal of Corporate Finance, 14(4), 431-445.

Anderson, R. \& Reeb, D. (2003a). Founding-family ownership and firm performance: evidence from the S\&P 500. The Journal of Finance, 58(3), 1301-1328.
Anderson, R. \& Reeb, D. (2003b). Founding family ownership, corporate diversification, and firm leverage. Journal of Law and Economics, 46(2), 653-684.

Anderson, R., Duru, A. \& Reeb, D. (2012). Investment policy in family controlled firms. Journal of Banking \& Finance, 36(6), 1744-1758.

André, P., Ben-Amar, W. \& Saadi, S. (2012). Family firms and high technology mergers \& acquisitions. Journal Management \& Governance, 17(59), 1997-2013.

Basu, N., Dimitrova, L. \& Paeglis, I. (2009). Family control and dilution in mergers. Journal of Banking \& Finance, 33(5), 829-841.

Bianco, M., Bontempi, M., Golinelli, R. \& Parigi, G. (2013). Family firms' investments, uncertainty and opacity. Small Business Economics, 40(4), 1035-1058.

Bjursell, C. (2011). Cultural divergence in merging family businesses. Journal of Family Business Strategy, 2(2), 69-77.

Block, J., Jaskiewicz, P. \& Miller, D. (2011). Ownership versus management effects on performance in family and founder companies: a bayesian reconciliation. Journal of Family Business Strategy, 2(4), 232-245.

Bouzgarrou, H. \& Navatte, P. (2013). Ownership structure and acquirers performance: Family vs. non-family firms. International Review of Financial Analysis, 27(2), 123-134.

Cai, D., Luo, J-H. \& Wan, D-F. (2012). Family CEOs: Do they benefit firm performance in China? Asia Pacific Journal Management, 29(4), 923-947.

Caprio, L., Croci, E. \& Del Giudice, A. (2011). Ownership structure, family control, and acquisition decisions. Journal of Corporate Finance, 17(5), 1636-1657.

Chi, J., Sun, Q. \& Young, M. (2011). Performance and characteristics of acquiring firms in the Chinese stock markets. Emerging Markets Review, 12(2), 152-170.

Claessens, S., Djankov, S. \& Lang, L. (2000). The separation of ownership and control in East Asian corporations. Journal of Financial Economics, 58(1-2), 81-112.

Corrar, L., Paulo, E. \& Dias Filho, J. (2007). Análise multivariada para os cursos de Administração, Ciências Contábeis e Economia. Selo Editorial: Atlas

Faccio, M. \& Lang, L. (2002). The ultimate ownership of Western European corporations. Journal of Financial Economics, 65(3), 365-395.

Faccio, M., Marchica, M. \& Mura, R. (2011). Large shareholder diversification and corporate risk-taking. Review of Financial Studies, 24(11), 3601-3641.

Feito, I. \& Menéndez, S. (2010). Family firm mergers and acquisitions in different legal environments. Family Business Review, 23(1), 60-75.

Ferreira, M., Santos, J., Almeida, M. \& Reis, N. (2014). Mergers $\&$ acquisitions research: a bibliometric study of top strategy and international business journals, 1980-2010. Journal of Business Research, 67(12), 2550-2558.

Gallo, M., Tàpies, J. \& Cappuyns, K. (2004). Comparison of family and nonfamily business: Financial logic and personal preferences. Family Business Review, 17(4), 303-318. 


\section{INFLUÊNCIA DA ESTRUTURA DE PROPRIEDADE E DO GERENCIAMENTO FAMILIAR SOBRE O POSICIONAMENTO EM FUSÕES E AQUISIÇÕES}

Gleason, K., Pennathur, A. \& Wiggenhorn, J. (2014). Acquisitions of family owned firms: boon or bust? Journal of Economics and Finance, 38(2), 269-286.

Gómez, L., Nunez, M. \& Gutierrez, I. (2001). The role of family ties in agency contracts. Academy of Management Journal, 44(1), 81-95

Gómez, L., Makri, M. \& Kintana, M. (2010). Diversification Decisions in Family Controlled Firms. Journal of Management Studies, 47(2), 223-252.

Gómez, L., Cruz, C., Berrone, P. \& Castro, J. (2011). The bind that ties: Socioemotional wealth preservation in family firms. Academy of Management Annals, 5(1), 653-707.

Gonenc, H., Hermes, N. \& Van Sinderen, E. (2013). Bidders gains and family control of private target firms. International Business Review, 22(5), 856-867.

Granata, D. \& Chirico, F. (2010). Measures of value in acquisitions: family versus nonfamily firms. Family Business Review, 23(4), 341-354.

Grossman, S. \& Hart, O. (1986). The costs and benefits of ownership: A theory of vertical and lateral integration. Journal of Political Economy, 94(4): 691-719.

Gugler, K., Ivanova, N. \& Zechner, J. (2014). Ownership and control in Central and Eastern Europe. Journal of Corporate Finance, 26(1), 145-163.

Hair Jr, J., Anderson, R., Tatham, R. \& Black, W. (2005). Análise multivariada de dados (5. ed.). Porto Alegre: Bookman.

Harding, D. \& Rovit, S. (2005). Garantindo o sucesso em fusões e aquisições: quatro decisões-chave para a sua próxima negociação. Rio de Janeiro: Campus.

Hiebl, M. (2012). Peculiarities of financial management in family firms. International Business \& Economics Research Journal, 11(3), 315-322.

Holmen, M. \& Nivorozhkin, E. (2007). The impact of family ownership and dual class shares on takeover risk. Applied Financial Economics, 17(10), 785-804.

Huybrechts, J., Voordeckers, W. \& Lybaert, N. (2012). Entrepreneurial risk taking of private family firms: The influence of a nonfamily CEO and the moderating effect of CEO tenure. Family Business Review, 26(2), 161-179.

Jiang, Y. \& Peng, M. W. (2011). Are family ownership and control in large firms good, bad, or irrelevant? Asia Pacific Journal of Management, 28(1), 15-39.

La Porta, R., Lopez-De-Silanes, F. \& Shleifer, A. (1999). Corporate ownership around the world. Journal of Finance, 54(2), 471-517.

Lemes Jr, A., Rigo, C. \& Cherobim, A. (2002). Administração financeira: princípios fundamentos e práticas brasileiras (5. ed.). Rio de Janeiro: Elsevier.
Leung, S., Richardson, G. \& Jaggi, B. (2014). Corporate board and board committee independence, firm performance, and family ownership concentration: an analysis based on Hong Kong firms. Journal of Contemporary Accounting \& Economics, 10(1), 16-31.

McConaughy, D. (2000). Family CEOs vs. Nonfamily CEOs in the family controlled firm: an examination of the level and sensitivity of pay to performance. Family Business Review, 13(2), 121-131.

McConaughy, D., Matthews, C. \& Fialko, A. (2001). Founding family controlled firms: performance, risk and value. Journal of Small Business Management, 39(1), 31-49.

Mickelson, R. \& Worley, C. (2003). Acquiring a family firm: A case study. Family Business Review, 16(4), 251-268.

Miller, D., Le Breton-Miller, I., Lester, R. \& Cannella Jr., A. (2007). Are family firms really superior performers? Journal of Corporate Finance, 13(5), 829-858.

Miller, D., Le Breton-Miller, I. \& Lester, R. (2010). Family ownership and acquisition behavior in publicluy traded companies. Strategic Management Journal, 31(2), 201-223.

Mishra, C. \& McConaughy, D. (1999). Founding family control and capital structure: The risk of loss of control and the aversion to debt. Entrepreneurship Theory and Practice (Summer), 53-64.

Schmid, T. (2013). Control considerations, creditor monitoring, and the capital structure of family firms. Journal of Banking \& Finance, 37(2), 257-272

Shim, J. \& Okamuro, H. (2011). Does ownership matter in mergers? A comparative study of the causes and consequences of mergers by family and non-family firms. Journal of Banking and Finance, 35(1), 193-203.

Steijvers, T. \& Voordeckers, W. (2009). Collateral and credit rationing: a review of recent empirical studies as a guide for future research. Journal of Economic Surveys, 23(5): 924-946.

Su, W. \& Lee, C-Y. (2013). Effects of corporate governance on risk taking in Taiwanese family firms during institutional reform. Asia Pacific Journal of Management, 30(3), 809-828.

Tsai, W., Kuo, Y. \& Hung, J. (2009). Corporate diversification and CEO turnover in family business: self-entrenchment or risk reduction. Small Business Economics, 32(1), 57-76.

Villalonga, B. \& Amit, R. (2006). How do family ownership, control and management affect firm value? Journal of Financial Economics, 80(2), 385-417.

Yoo, K., Lee, Y. \& Heo, E. (2013). Economic effects by merger and acquisition types in the renewable energy sector: An event study approach. Renewable and Sustainable Energy Reviews, 26(10), 694-701. 